\title{
Impact of Building Energy Code on Energy Consumption at City Level - A study in the context of Ahmedabad, India
}

\author{
Rajan Rawal ${ }^{1}$, Kartikay Sharma ${ }^{1}$, Himani Pandya ${ }^{1}$ \\ ${ }^{1}$ Centre for Advanced Research in Building Science and Energy, CEPT University, Ahmedabad.
}

\begin{abstract}
This paper demonstrates the impact of Energy Conservation Building Code (ECBC), India implementation in the city of Ahmedabad India. The study uses available administrative and property tax data from the local government in conjunction with building energy simulation to estimate the benefits of various energy conservation measures (ECM) proposed in the ECBC. The study compares ECM between two versions of the code titled ECBC 2007 and ECBC 2017. It also investigates the impact of three stringencies defined in ECBC 2017. The paper establishes the energy saving impact due to only envelop measures, due to Envelope \& HVAC measures combined and due to the deployment of all ECM mandated in the ECBC. To envisage the impact of ECM at the city level the paper estimates growth in floor space up to the year 2047 and then attempts to envisage energy saving potential. Selection of 2047 is based on its significance since India will celebrate the $100^{\text {th }}$ year of its independence. The paper also attempts to estimate future saving potential in event of code implementation. The paper correlates the amount of floor space of various types of buildings in the city with total energy saving potential due to the partial deployment of code only for certain types of buildings. It also estimates savings due to partial compliance of code for certain building types based on ease of implementation i.e. it estimates $6 \%$ savings if all large office buildings in the city meet only envelop requirement of ECBC 2017 but $27 \%$ savings in the event of enforcement of all ECM of ECBC 2017. The paper helps to understand the impact of various building types and impact of various ECM at the building level and at the city level. The paper provides valuable guidance to policymakers for code implementation and enforcement of code based on various stringencies and/or based on the implementation and enforcement scope of the code.
\end{abstract}

\section{Introduction}

India has pledged to reduce its emission intensity during the United Nations Framework Convention on Climate Change (UNFCCC) in Paris. It declared its Nationally Determined Contributions (NDC) during the same time (UNFCCC, 2015). India has experienced sustained economic growth since the last two decades leading to increasing per capita income. This leads to higher sales of white goods including comfort goods such as air conditioners. As an impact of such economic activities in recent times India has seen a rise in per capita electricity consumption. At present the per capita consumption of electricity which stands at around $1120 \mathrm{kWh}$ per year
(Central Electricity Authority, 2017) much lower than many countries, but the rate of increase is much higher than rest of the world (International Energy Agency, 2017). Out of approximately 1210.2 million people in total about 369.8 (31\%), million people are residing in the urban area. The growth of urbanization in India stands at approximately $2.07 \%$ which appears to be less in percentage terms but looking at absolute numbers of the population it is significant. It translates into an increase of about 24 million people per year in the urban area. Such context has lead unprecedented growth in the commercial building sector (AEEE, 2018) as well as residential building sector. It is estimated that 1160 million $\mathrm{m}^{2}$ commercial floor space in 2017-18 will increase by 2.7 times to 3090 million $\mathrm{m}^{2}$ by 2030 . Along with this percentage air-conditioned area will increase from presently $26 \%$ to $54 \%$ by $2037-38$. India enacted Energy Conservation Act in 2001. As a result of it in 2007 Bureau of Energy Efficiency (BEE), India developed Energy Conservation Building Code 2007. This version of the code was applicable to all commercial building either having connected load greater than $500 \mathrm{~kW}$ or contract electric demand of $600 \mathrm{kVa}$ at the time of its launch. Subsequently, eligibility criterion revised to a connected load of $100 \mathrm{~kW}$ or contract electric demand of $110 \mathrm{kVa}$. 2007 version of ECBC did not differentiate between various typologies of commercial buildings. Subsequent to the 2007 version in 2017 updated version of ECBC was developed and launched. This version of ECBC provides a recommendation for 16 various types of commercial buildings having connected load greater than $100 \mathrm{~kW}$ or electric demand greater than $120 \mathrm{kVa}$, similar to the 2007 version. The ECBC 2007 and ECBC 2017 both contain predominantly two compliance approach, one prescription based and second performance-based. While the ECBC 2007 does contain only one level of stringency, ECBC 2017 provides an option to comply with any one of the stringencies namely ECBC 2017, ECBC+ 2017 (ECBC Plus 2017) and Super ECBC 2017.

ECBC implementation not only saves energy but also helps to reduce peak demand since buildings will consume less electricity during harsh outdoor conditions due to efficient envelop and HVAC system. ECBC Compliant building will have less thermal transfer through building envelope, which will reduce variation in cooling load over the day and during various seasons. Number of case studies demonstrates reduction in peak load at building level due to code compliant specifications of building envelope (EESL BEEP, Bhatnagar, Varma, Tathagat, \& Diddi, 2017). Code implementation also helps expand the market for building material, equipment and services help achieve energy efficient building. Such 
expansion of market help increases economic activities in the region leading to better quality of life. In India powers to implement such code lies with state government. Successful implementation of ECBC in India requires the state government to adopt and mandate it. Based on the mandate from state government, urban local government is responsible for the enforcement of it in their administrative region. Demonstrating quantifiable benefits of ECBC adoption, implementation and enforcement at the urban local government level could lead to early adoption of ECBC by policymakers. To envisage impact of the ECBC at the urban local level, understanding of the extent of existing floor space, its use is important. Based on the existing scenario it is vital to envisage future floorspace scenario and associated energy scenario.

ECBC enforcement in India experiences significant challenges (Kumar, Kapoor, Rawal, Seth, \& Walia, 2010; Rawal, 2013; Rawal et al., 2012). In the past various studies have proved that deconstructing ECBC into the easily implementable form will increase the probability of adoption, implementation, and enforcement. Easy to implementable tiers will access market size and benefits at each tier. Definition of tiers can take into the account availability of resources at utility companies, the capacity of energy consultancy service providers, building material manufacturers, and suppliers, Building Monitoring Services Company and HVAC companies to access future demand in time scale.

To meet the objective of the study, authors have identified three distinct but interdependent activities (i) Estimating current floor space of a city (ii) Estimating energy savings due to various ECM prescribed or recommended as part of ECBC. (iii) Aggregating energy consumption at city level building future scenarios.

\section{Literature review}

During the last decade, several authors have attempted to establish a city scale or urban scale building energy use modeling methods. These are based on various approaches. Li et al (2017) reviewed several research papers and provided the broad categories of the energy models. They categorized models based on the workflow of physics-based models, bottom-up models and their applicability at the urban scale. They recognized significant differences across models and discussed challenges attached with model preparation and validation. Tornberg \& Thuvander (2012) successfully worked on linking GIS, remote sensing technology and building a stock model to develop an energy model of Goteborg. They demonstrated that by encoding geographical data and energy data from different sources it is possible to develop the integrated model. Buffat, Froemelt, Heeren, Raubal, \& Hellweg (2017) proposed a model based on GIS data to model heat demand of large regions having higher density of buildings, primarily urban areas. They used a digital elevation model, climate classification and location dependent effects to generate models. The combination of building energy simulation and GIS method was used by Heiple \& Sailor (2008) and demonstrated by conducting a contextual study with reference to the city of Houston in the USA. They used this method to support an argument for anthropogenic sensible and latent waste heat emissions associated with building energy consumption and urban heat island studies. Hong, Zhou, Fridley, Feng, \& Khanna (2014) identified key socioeconomic drivers of growth to predict annual growth in floor space. They used energy consumption to calculate the demand for energy in the building as well as demand for building material. Using 3D stock Evans, Liddiard, \& Steadman (2019) suggested that while developing building stock model one should account for interior space volumes and not only just floor space to account quantity for energy use within the building. The same study gives a higher emphasis on the importance of characterizing mixed-use buildings more carefully then buildings having a single use. Mixed-use buildings were defined as buildings having more than one type of activities on various floors. It does have to recognize the presence of different floor space with different use or same floor space with different users based on time of the day or time of the year. Zavrl, Stegnar, Rakušček, \& Gjerkeš (2016) developed bottomup building stock energy mode by identifying data sources available in the public domain. They applied the model in Kocevje city and demonstrated that model is applicable for creating a correct baseline for energy consumption in an existing building as well as it can be used for deciding retrofit strategies in existing building stock.

It is well documented that the top-down model is based on statistical relationships between socioeconomic factors, climate context, gross domestic product, and energy consumption in the building at the macro level. As against the bottom-up model rely on the estimation of the energy consumption of the individual buildings considering end-use consumption, characteristics of the buildings and then aggregates them at the city level. Sometimes these approaches depend upon statistical relationships and sometimes they depend upon physicsbased principles. Top-down models are capable of modeling relationships between economic and energy demand variables, but the bottom-up model can determine typical end-use energy consumption. While the top-down approach uses aggregated datasets, bottom-up models include micro details including building occupant behaviors. The top-down approach does not deal with technical details and is less capable of considering uncertainties in the model. At the same time, the bottomup approach needs large data and depends upon the quality of historical data. (Lim, 2017).

\section{Methodology}

Floor space estimation: Relying on administrative data from urban local body i.e. Ahmedabad Municipal Corporation (AMC) to access existing building stock was the first stage of the study. The second stage was to develop a building energy model for all 16 typologies of commercial buildings representing various building types in the city of Ahmedabad. And define the impact of each 
ECM as per various versions and stringencies of ECBC, The third step was to aggregate data regarding the existing building stock and energy consumption numbers to estimate current energy consumption in commercial buildings. The third stage also includes future energy savings estimation.

\begin{tabular}{|c|c|c|c|}
\hline $\begin{array}{c}\text { Administrative Data } \\
\text { (Property Tax) }\end{array}$ & GIS data & $\begin{array}{l}\text { Commercial Building } \\
\text { Energy Models }\end{array}$ & $\begin{array}{l}\text { Energy Saving } \\
\text { Potential of a building }\end{array}$ \\
\hline \multicolumn{2}{|c|}{ Building Stock Estimate } & $\begin{array}{l}\text { Estimation of Energy } \\
\text { Coesumption }\end{array}$ & \multirow{2}{*}{$\begin{array}{l}\text { Energy Saving } \\
\text { potential in case of } \\
\text { implementation of } \\
\text { Energy Cade }\end{array}$} \\
\hline \multicolumn{3}{|c|}{ City level energy coesumption } & \\
\hline \multicolumn{4}{|c|}{ Presens and Future City Level Energy Savings } \\
\hline
\end{tabular}

Figure 1: Methodology Sketch

Various database of AMC was studied, these include database from the town planning department, property tax department, water-sanitation department, energy efficiency cell, and roads \& building department. It was found that the town planning department has information about building geometry and use on each property within the administrative limits of the AMC but does not contain it in a single dataset. GIS map available at the town planning department is not fully correctly geotagged with information about floor space and use. It was found that property tax department data contains useful information for the study and data which can be compared with GISbased data. Property tax data contained floor space, use type of the building, and age of the building. The property tax data found to be more reliable data because of endorsement of data by each property owner for its correctness. It was the considerable exercise to make database appropriate for the study The GIS data was verified and was corrected using various sources of data. Corrections were based on data available in research and academic institutes such as Faculty of Planning CEPT University, Urban Management Centre, Ahmedabad and All India Institute of Local Self-Government. The authors of this paper were possessing a certain level of Ahmedabad city information pertaining to town planning scheme and land use plan of the city, all this information was used to verify data and corrected version was used for this study. Each road width was verified with land use plan of the city because of general Development Control Regulations (GDCR) prescribes building set back margins and height of the building based on road width and location of the plot. This exercise was helpful in arriving at correct building floor space in Ahmedabad which was then compared with property tax data.

As per $74^{\text {th }}$ amendment in the constitution of India pertaining to urban local bodies and administrative reforms at ULB levels in India (Government of India, 1950) each ULB is required to generate their own revenue to support their existing infrastructure, services, and development activities. Property tax is one of the most revenue generating tool for ULB. Property tax database has widely used the instrument to collect annual property tax within the city and contains one of the most reliable information on floor-space, its associated use and vintage value of the property. This exercise provided total building floor space in the city of Ahmedabad along with the use of the floor space.

Out of 621 million $\mathrm{m}^{2}$ constructed floor space exists in Ahmedabad in 2017, approximately 101 million $\mathrm{m}^{2}$ accommodates one of the activities of 16 commercial activity, which is $16.2 \%$ commercial floor space to total Total Floor space (621 million $\mathbf{m}^{2}$ )

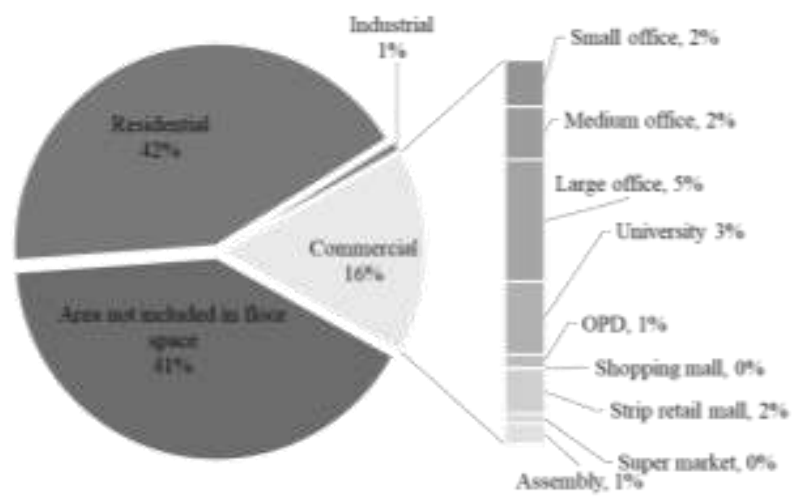

Figure 2: Floor space distribution for Ahmedabad city

floor space of Ahmedabad city. Out of which $32 \%$ is for large offices $(5.1 \%$ of total floor area), $19 \%$ is for educational purpose ( $3.05 \%$ of total floor area), $14 \%$ is for medium offices (2.25\% of total floor area), $12 \%$ each is for small office and standalone retail shops $(1.93 \%$ of total floor area).

Energy saving potential of various versions and tiers of ECBC: The second stage of the study was to create energy models for the baseline scenario and code implementation scenarios. During the development of ECBC 2017, Bureau of Energy Efficiency (BEE) as part of a project titled 'Partnership to Advance Clean Energy - Development' supported by USAID India arrived at the input parameters for all 16 types of commercial building energy models. After consensus from technical committee of experts from various sectors, constituted by BEE energy model input parameters were finalized by BEE. Authors of this paper received permission to use all those input parameters to conduct this study. EnergyPlus version 8.6 (U.S. Department of Energy, 2016) was used to develop energy models for 16 commercial building types. BEE defined 16 building types based on building typology defined in National Building Code 2016 (Bureau of Indian Standards, 2016). Table 1 lists these.

Table 1: Building Typology identified as part of ECBC 2017

\begin{tabular}{|l|l|l|}
\hline \multicolumn{3}{|l|}{ Commercial Building Types as per ECBC 2017} \\
\hline Office & 1 & Small Office \\
\cline { 2 - 3 } & 2 & Medium Office \\
\cline { 2 - 3 } & 3 & Large Office \\
\hline Academia & 4 & University Academic \\
\hline
\end{tabular}




\begin{tabular}{|l|l|l|}
\hline \multirow{2}{*}{} & 5 & Primary School \\
\cline { 2 - 3 } Health-care & 6 & Secondary School \\
\cline { 2 - 3 } buildings & 7 & 150 Bed IPD Hospital \\
\cline { 2 - 3 } Retail & 8 & OPD Outpatient Centre \\
\cline { 2 - 3 } & 10 & Super Market \\
\cline { 2 - 3 } & 11 & Opopping Mall \\
\cline { 2 - 3 } & 12 & Strip Retail Mall \\
\hline \multirow{3}{*}{ Hospitality } & 13 & 4 or 5 Star Hotel \\
\cline { 2 - 3 } & 14 & Resort type Hotel \\
\cline { 2 - 3 } & 15 & No Star Hotel \\
\hline Assembly & 16 & Assembly \\
\hline
\end{tabular}

Building geometry, typical floor area, number of floors building envelop characteristics, HVAC characteristics, operation schedule, lighting power density (LPD) and equipment power density (EPD) were considered from the baseline models developed by BEE as discussed earlier in this paper. For each building type, a separate baseline model was developed. To provide an insight into the nature of input values used to generate the baseline model, as an example, the following table demonstrating input used for large office building baseline model.

Table 2: Input parameters Baseline building (Large office)

\begin{tabular}{|c|c|}
\hline \multicolumn{2}{|c|}{ Example of Baseline Building Input Parameters } \\
\hline \multicolumn{2}{|l|}{ Building Geometry } \\
\hline Building shape & Rectangle \\
\hline No of floor & 12 \\
\hline Total floor area & $50000 \mathrm{~m}^{2}$ \\
\hline Conditioned area $(\%)$ & 80 \\
\hline Aspect Ratio & $1: 2(82.0 \mathrm{~m} \mathrm{x} 41.0 \mathrm{~m})$ \\
\hline No of basement & 3 \\
\hline Floor plate & $3300 \mathrm{~m}^{2}$ \\
\hline Basement area & $8200 \mathrm{~m}^{2}$ \\
\hline F/F height & $4.2 \mathrm{~m}$ \\
\hline False ceiling height & $0.9 \mathrm{~m}$ \\
\hline \multicolumn{2}{|c|}{ Building envelope specifications } \\
\hline Roof U-Value & $2.99 \mathrm{~W} / \mathrm{m}^{2} . \mathrm{K}$ \\
\hline Wall U-Value & $1.58 \mathrm{~W} / \mathrm{m}^{2} . \mathrm{K}$ \\
\hline WWR & $42 \%$ (with $0.9 \mathrm{~m}$ high sill) \\
\hline
\end{tabular}

\begin{tabular}{|l|l|}
\hline Window U-Value & $2.4 \mathrm{~W} / \mathrm{m}^{2} . \mathrm{K}$ \\
\hline S.H.G.C, \& V.L.T & 0.29 (SHGC), 0.37 (VLT) \\
\hline Shading & No \\
\hline HVAC System Specifications \\
\hline HVAC System & Centrifugal chiller \\
\hline C.O.P. & $5.2(2.8$ for WH climate) \\
\hline A.H.U. & Constant Air Volume \\
\hline Pump | efficiency & Variable (70\%) \\
\hline Condenser type & Water (single speed, \\
\hline Ventilation & Centrifugal Fan \\
\hline Heating system & Electric Resistance \\
\hline Operation Schedule $($ Weekends off) \\
\hline Schedule & 9 am -6 pm \\
\hline Cooling setpoint $\left({ }^{\circ} \mathrm{C}\right)$ & $24 / 60 \%$ RH \\
\hline Heating setpoint $\left({ }^{\circ} \mathrm{C}\right)$ & $20 / 60 \%$ RH \\
\hline Occupancy $\mathrm{m}^{2} /$ person & 0.156 \\
\hline Lighting \& Equipment Density \\
\hline Lighting load $\left(\mathrm{W} / \mathrm{m}^{2}\right)$ & 11.9 \\
\hline Equipment load $\left(\mathrm{W} / \mathrm{m}^{2}\right)$ & 19.0 \\
\hline
\end{tabular}

Total four stringencies were modeled and studied. One stringency scenario of (i) ECBC 2007 version and three stringencies scenarios of ECBC 2017 namely (ii) ECBC, (iii) $\mathrm{ECBC}+(\mathrm{ECBC}$ Plus) and (iv) Super ECBC were simulated for three tiers. These three tiers were considered based on ease of implementation and energy-saving potential (Rawal, Vaidya, Ghatti, Manu, \& Chandiwala, 2013; Rawal et al., 2012). Tier 1 includes building envelop related ECM such as wall, roof, and fenestrations. Tier 2 includes building envelop and HVAC related ECM such as efficiency of HVAC components and Tier 3 includes all ECM mentioned in various versions of ECBC. Following table summarising all approaches adopted to estimate energy saving potential. The table also indicate energy performance index (EPI) calculated in $\mathrm{kWh} / \mathrm{m}^{2}$-Year for each tier and for all 16 building type. 
Table 3: Complied EPI for all version of ECBC and all Tiers of ECBC

\begin{tabular}{|c|c|c|c|c|c|c|c|c|c|c|c|c|c|c|c|c|c|}
\hline \multicolumn{2}{|c|}{$\begin{array}{c}\text { EPI } \\
\text { kWh/m²/year }\end{array}$} & 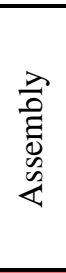 & 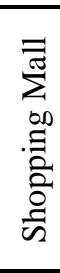 & 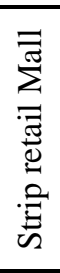 & 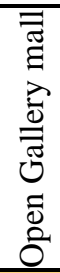 & 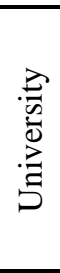 & 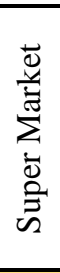 & 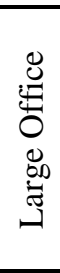 & $\begin{array}{l}\stackrel{0}{\Xi} \\
\stackrel{0}{0} \\
\stackrel{0}{0}\end{array}$ & 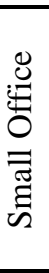 & 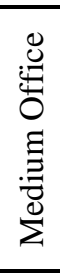 & 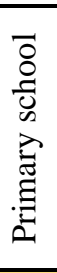 & 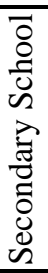 & 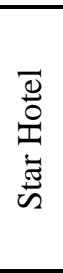 & 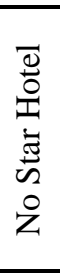 & 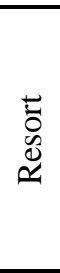 & 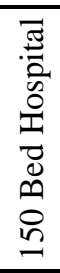 \\
\hline & BAU & 202 & 198 & 197 & 124 & 149 & 143 & 138 & 111 & 76 & 172 & 66 & 56 & 199 & 92 & 197 & 223 \\
\hline \multirow{4}{*}{$\begin{array}{c}\text { Tier } \\
1\end{array}$} & ECBC-07 & 178 & 176 & 153 & 114 & 128 & 136 & 135 & 102 & 71 & 149 & 64 & 51 & 186 & 84 & 129 & 212 \\
\hline & ECBC-17 & 176 & 179 & 173 & 118 & 128 & 139 & 135 & 102 & 72 & 149 & 63 & 55 & 187 & 85 & 141 & 213 \\
\hline & $\begin{array}{l}\text { ECBC- } \\
17 \text { plus }\end{array}$ & 173 & 176 & 168 & 117 & 126 & 137 & 135 & 102 & 72 & 148 & 63 & 55 & 184 & 84 & 132 & 211 \\
\hline & $\begin{array}{l}\text { ECBC-17 } \\
\text { super }\end{array}$ & 172 & 169 & 165 & 115 & 118 & 134 & 133 & 101 & 72 & 147 & 63 & 54 & 181 & 82 & 121 & 211 \\
\hline \multirow{4}{*}{$\begin{array}{c}\text { Tier } \\
2\end{array}$} & ECBC-07 & 177 & 163 & 345 & 148 & 101 & 191 & 97 & 135 & 93 & 128 & 87 & 62 & 116 & 172 & 236 & 165 \\
\hline & ECBC-17 & 121 & 167 & 150 & 141 & 91 & 144 & 103 & 83 & 74 & 101 & 65 & 55 & 76 & 83 & 130 & 165 \\
\hline & $\begin{array}{l}\text { ECBC-17 } \\
\text { plus }\end{array}$ & 117 & 165 & 150 & 140 & 87 & 141 & 96 & 83 & 75 & 92 & 59 & 56 & 72 & 78 & 116 & 164 \\
\hline & $\begin{array}{l}\text { ECBC-17 } \\
\text { super }\end{array}$ & 115 & 154 & 146 & 136 & 83 & 134 & 93 & 83 & 75 & 88 & 57 & 54 & 69 & 75 & 106 & 162 \\
\hline \multirow{4}{*}{$\begin{array}{c}\text { Tier } \\
3\end{array}$} & ECBC-07 & 164 & 153 & 320 & 135 & 92 & 173 & 88 & 131 & 84 & 102 & 80 & 57 & 113 & 168 & 221 & 162 \\
\hline & ECBC-17 & 102 & 146 & 117 & 108 & 79 & 115 & 85 & 67 & 48 & 95 & 53 & 51 & 67 & 72 & 112 & 160 \\
\hline & $\begin{array}{l}\text { ECBC-17 } \\
\text { plus } \\
\end{array}$ & 96 & 138 & 105 & 109 & 69 & 105 & 81 & 62 & 44 & 82 & 47 & 43 & 58 & 63 & 90 & 158 \\
\hline & $\begin{array}{l}\text { ECBC-17 } \\
\text { super }\end{array}$ & 90 & 116 & 82 & 92 & 56 & 90 & 76 & 53 & 40 & 70 & 44 & 34 & 50 & 54 & 72 & 152 \\
\hline
\end{tabular}

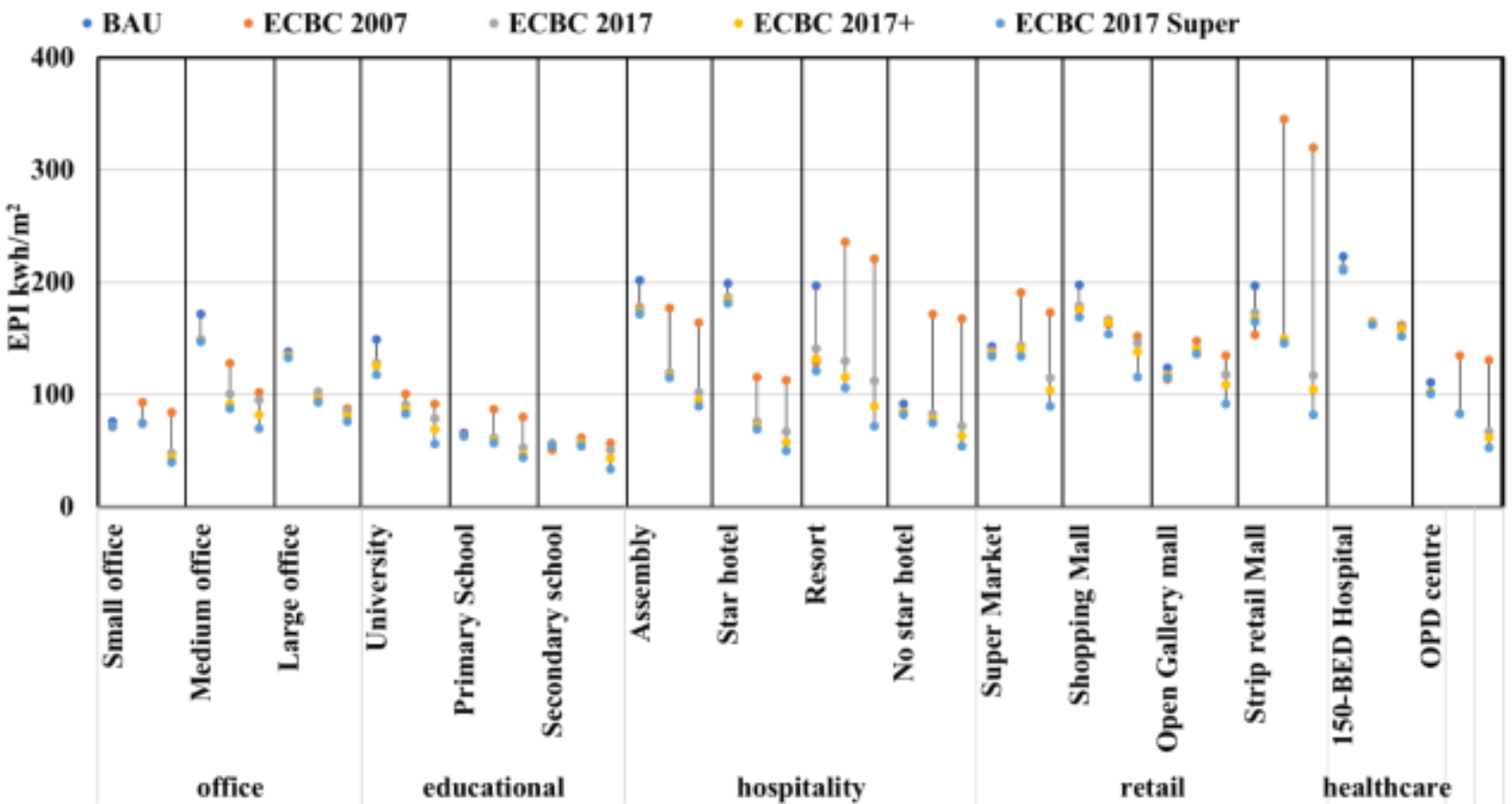

Figure 3: Reduction in EPI due to versions of ECBC and Tiers of ECBC 
Aggregation of the impact of ECM at city level: Energy consumption for buildings at city level was dependent on the existing building stock for which data was derived using GIS and property tax sources and energy consumption of each commercial building type was derived using energy models. Compounded Annual Growth Rate (CAGR) was considered for the basis to predict future growth in floor space. Based on historical data between 1950 and 2015 from the property tax department earlier study by the same authors derived $3.18 \%$ CAGR growth for commercial floor space in Ahmedabad (CEPT University, 2016). This is closer to study conducted for national level projection by Lawrence Berkeley National Laboratory. For the purpose of the study, it was assumed that in 2018 , only $10 \%$ of the new commercial buildings will meet code compliance and compliance rate will increase at $10 \%$ every year. This assumption was based on consumer awareness and capabilities of ULB to manage code enforcement. It was assumed that by 2027 all commercial building added between 2018 and 2017 will meet code compliance. It was assumed that in $201810 \%$ new buildings will be compliance with ECBC 2007, between 2019 and 2021 newly added buildings will comply ECBC 2017. From 2022, 90\% new building will keep complying to ECBC 2017 version but $10 \%$ will adopt ECBC 2017 Plus version for compliance until 2027. Introduction of ECBC 2017 Super will come in force by 2017 and then onwards every year 10\% new buildings will comply ECBC 2017. Basis of assumptions for compliance rates was based on national level targets set by organizations such as Bureau of Energy Efficiency and NITI Aayog. (IESS2047,BEE2017). Due to increasing economic pressure on land price every city does experience the transformation of the old building to new buildings. Old buildings will be replaced by bigger and taller buildings in the same land. Every ten years UBL do release new Town Planning Scheme and updated version of the entire city master plan. Observing the last 30 years of trends, authors have assumed $1.5 \%$ of replacement ratio between old buildings and new buildings. At this rate, $45 \%$ of 2017 commercial building stock will be replaced by new commercial building stock by 2047 , and these buildings are expected to comply with ECBC.

\section{Discussion:}

Building level: For a medium commercial building, version of 2007 can save up to 20,30 MWh of electricity whereas implementation of ECBC 2017 for the same building type can save 22,30 MWh units of electricity which is $230 \mathrm{MWh}$ units more than the ECBC 2007 version. Similarly, for a medium commercial building, savings from ECBC 2007 version envelope is 13\%, savings from HVAC added on the envelope is $26 \%$ and savings from full implementation of ECBC 2007 is $41 \%$. For the ECBC 2017 version, savings from the envelope is $14 \%$, savings from HVAC increases to 42 and savings from full implementation is $45 \%$. For ECBC 2017+ version, savings from the envelope is $14 \%$, which increases to $47 \%$ due to HVAC and from full implementation, it becomes $53 \%$. For the last stringency i.e. ECBC 2017 Super, savings from the envelope is $15 \%$, which increases to $50 \%$ due to $\mathrm{HVAC}$ and due to full implementation, it becomes $60 \%$.

If the only tier 1 measure are considered (i.e. envelope measures); For the ECBC 2017 version, in a large office building a minimum savings of $3 \mathrm{kWh} / \mathrm{m} 2 / \mathrm{year}$ is observed where-as maximum savings of $56 \mathrm{kWh} / \mathrm{m}^{2}$-year from the same measure is obtained in resort building. For ECBC 2017+ version for the same building types, savings from the envelope for a large office building is 3 $\mathrm{kWh} / \mathrm{m}^{2} /$ year and for resort building, it is $65 \mathrm{kWh} / \mathrm{m}^{2}$ year. Similarly, for the last version of ECBC 2017 i.e. ECBC 2017 Super version savings for a large office building is $5 \mathrm{kWh} / \mathrm{m}^{2} /$ year and savings for resort building is $76 \mathrm{kWh} / \mathrm{m}^{2} /$ year.

For tier 2 measures (i.e. Envelop + HVAC measures), the minimum savings of $9 \mathrm{kWh} / \mathrm{m}^{2} /$ year from ECBC 2017 version is observed in no-star hotel whereas same measures result into saving of $124 \mathrm{kWh} / \mathrm{m}^{2} /$ year for star hotel building type. For ECBC 2017 plus version, savings of $13 \mathrm{kWh} / \mathrm{m}^{2} /$ year is observed in no-star hotel and savings of $128 \mathrm{kWh} / \mathrm{m}^{2} /$ year is observed for the star hotel. For the final version of ECBC 2017 i.e. ECBC 2017 Super, savings of $17 \mathrm{kWh} / \mathrm{m}^{2} /$ year is observed in no-star hotel whereas savings of $130 \mathrm{kWh} / \mathrm{m}^{2} /$ year is observed in star hotel building type.

For the tier 3 measures (Full ECBC compliant), if we consider ECBC 2017 version, a minimum savings of 5 $\mathrm{kWh} / \mathrm{m}^{2} /$ year is observed for secondary school building whereas maximum savings of $100 \mathrm{kWh} / \mathrm{m}^{2} /$ year was observed for assembly type of building. For ECBC 2017 plus version, savings of $13 \mathrm{kWh} / \mathrm{m}^{2} /$ year is observed for secondary school and savings of $107 \mathrm{kWh} / \mathrm{m}^{2} /$ year is observed for assembly building type. For the last version of ECBC 2017 i.e. ECBC 2017 Super, savings of 22 $\mathrm{kWh} / \mathrm{m}^{2} /$ year is observed for the secondary school building and savings of $113 \mathrm{kWh} / \mathrm{m}^{2} /$ year is observed for assembly building.

City level: The study projects the energy demand for BAU scenario and energy savings achieved due to implementation for the year 2017 to the year 2047 for all version of ECBC 2007 and ECBC 2017.

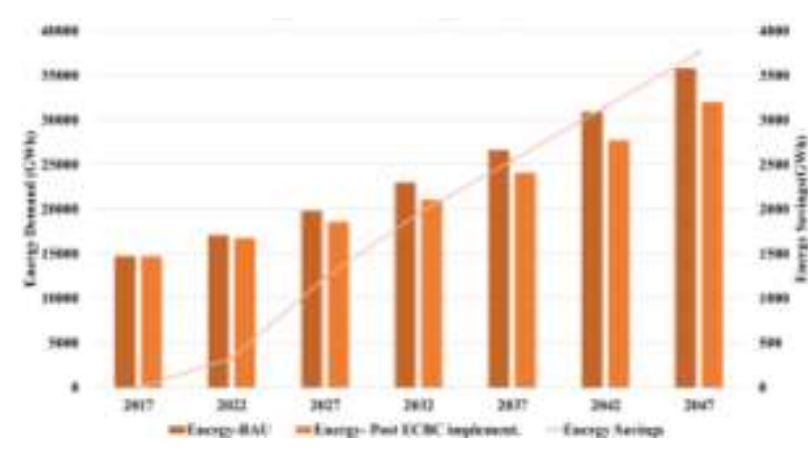

Figure 4: Energy demand and Energy savings potential for ECBC 2017 
For only ECBC 2017 version; If BAU trend is followed for the year 2017, the energy demand is $14772 \mathrm{GWh}$ and if same BAU trend is also followed for the year 2022, energy demand increases to $17152 \mathrm{GWh}$ which comes down to $16790 \mathrm{GWh}$ due to implementation of ECBC i.e. 334 GWH of energy demand is reduced due to implementation of ECBC. Similarly, for the year 2047, if BAU trend is followed Energy demand is $35855 \mathrm{GWh}$ and it decreases to $32090 \mathrm{GWh}$ due to Implementation of ECBC i.e. reduction of $3765 \mathrm{GWh}$ is observed.

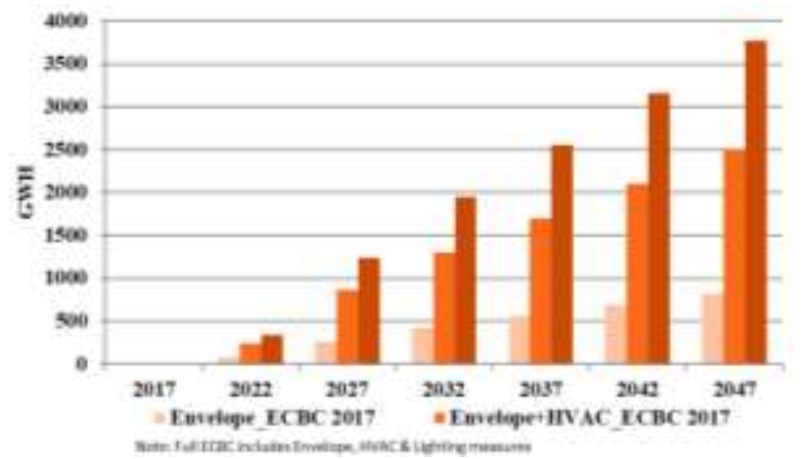

Figure 5: Energy savings from 3 different tiers of ECBC 2017
Figure 5 indicates the savings due to the 3 different tiers of ECBC 2017 version for the year 2017 to the year 2047. The minimum savings of $72 \mathrm{GWh}$ for the year 2022 is observed in Tier 1 i.e. Envelope measures followed by savings of $273 \mathrm{GWh}$ for tier 2 \& maximum savings of 334 GWh is observed for the Tier 3 i.e. Full ECBC compliant measures. For the year 2047, minimum savings of 817 GWh is observed by the implementation of tier 1 of ECBC 2017; followed by $2510 \mathrm{GWh}$ due to tier 2 measures and the maximum savings of 3765 savings due to the implementation of tier 3 of ECBC 2017.

Figure 6 explains the relation of the savings of a building type and its relationship with aggregated savings at the city level. The commercial building stock for Ahmedabad city consists of different building types and for obtaining the aggregated city-level energy, savings from each building type is added. As each building type possesses different characteristics and varying contribution in the total floor space composition of the city, behaviors of each building type are different from other. A building that has high level of energy savings potential at building level is not sure to have a high savings potential at city level due to its contribution in the total building stock

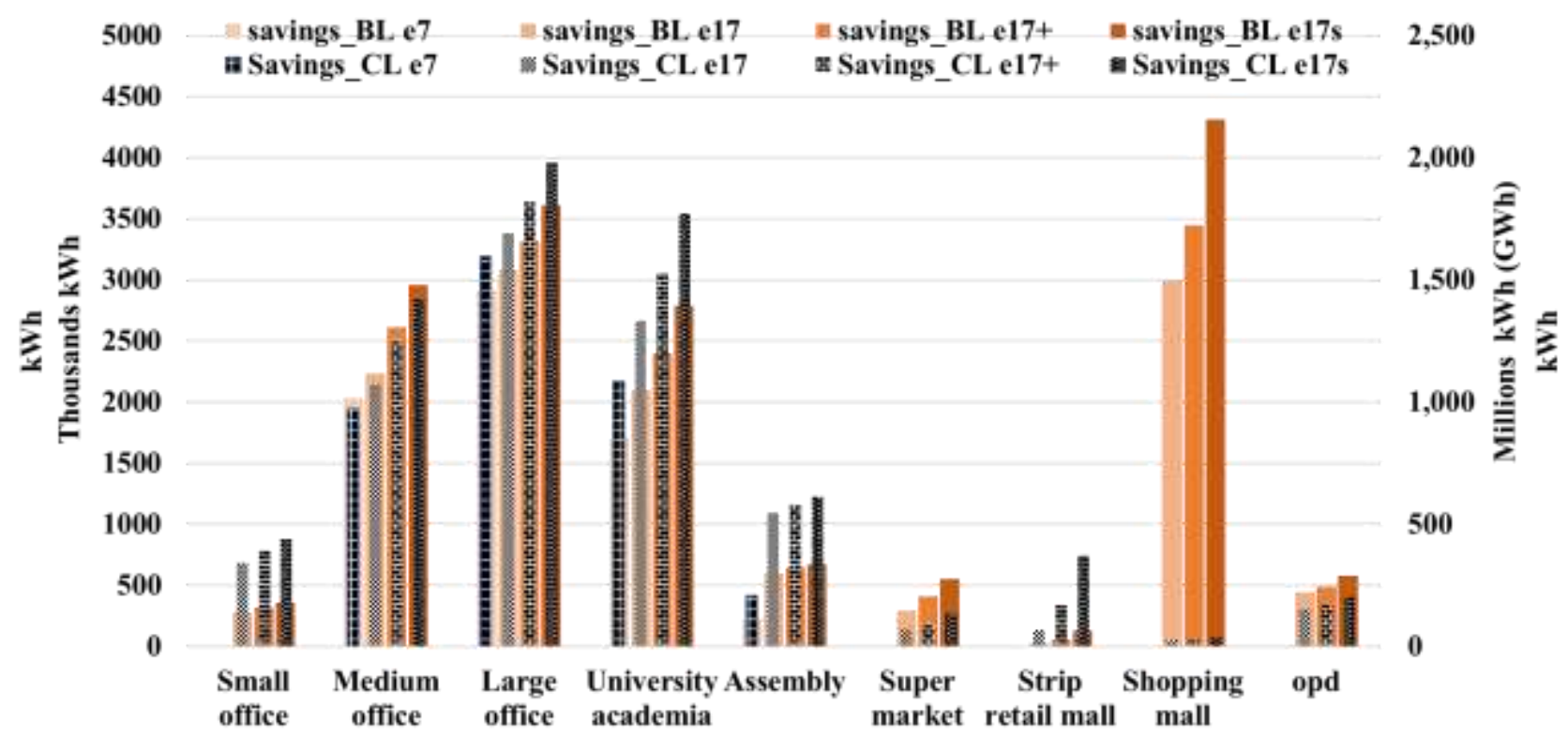

Figure 6: Contribution of building type on city level savings (BL indicates building level savings and CL indicates city level savings)

for e.g. as presented in figure 6 the building level savings for the shopping mall is highest compared to all other building but when the savings from all shopping mall are aggregated to the city level, the aggregated savings is very less compared to other building types but if same building level savings is observed for the strip-retail malls, the building level savings are minimal but when aggregated for city level the savings from Strip-retail mall is notable and higher than other 2 building types

As discussed before, ECBC implementation also helps in reducing the peak demand for the city level stakeholders. Minimum peak reduction of 1139 MW is observed for ECBC 2007 whereas maximum demand reduction of
$4743 \mathrm{MW}$ is observed due to the implementation of ECBC 2017 Super. These projections were compared with city level decadal master plan and state level GDP data. Building level data was validated and compared with other benchmarking studies based on sample survey method. However, it is to be noted that due to unavailability of city level floor space construction projection, validation of energy saving potential is challenging. 


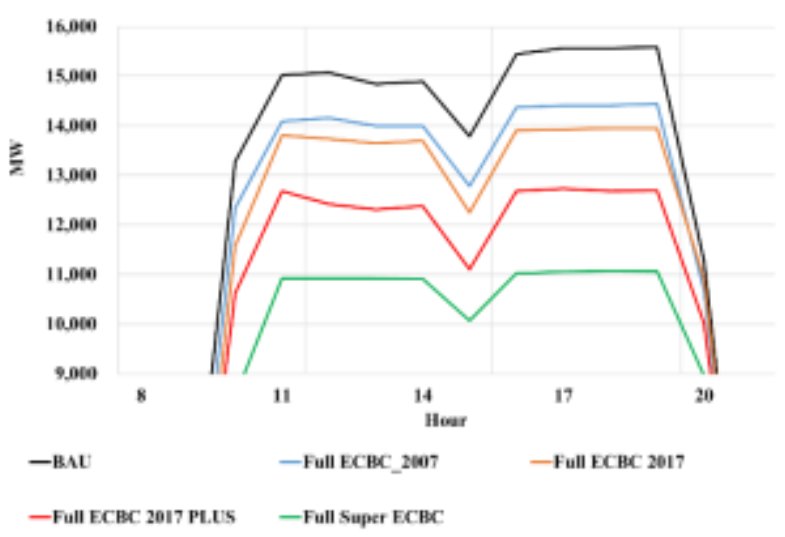

Figure 7: Peak load reduction due to ECBC

\section{Conclusion}

After understanding existing floor space use, the study also establishes city-level energy saving impact of ECBC and individual energy conservation measures within buildings. The study also estimates scenarios of floor space projection and associated energy savings due to code implementation. The study relies on building energy simulation, past research, and literature to determine and estimate the energy consumption of buildings. Paper establishes advantages of adopted methodology which is scalable at the state and national level; as most urban local bodies throughout the county have the mandate to collect property tax based on a unit of floor area. Such methodology promises to overcome the major barrier of robust data in establishing existing floor space.

\section{Acknowledgment}

Authors wish to express their sincere gratitude towards Shakti Sustainable Energy Foundation, Bureau of Energy Efficiency, and USAID PACE project team for their support to this work.

\section{References:}

AEEE. (2018). Building Stock Modelling. Retrieved from http://www.aeee.in/wpcontent/uploads/2018/09/Building-StockModeling-Revised-pager.pdf

Bhatnagar, M., Varma, P., Tathagat, T., \& Diddi, S. (2017). Model for Assessing Impact Of Energy Conservation Building Code.

Buffat, R., Froemelt, A., Heeren, N., Raubal, M., \& Hellweg, S. (2017). Big data GIS analysis for novel approaches in building stock modelling. Applied Energy, 208(May), 277-290. https://doi.org/10.1016/j.apenergy.2017.10.041

Bureau of Indian Standards. (2016). National Building code of India. 2016. Retrieved from https://ia800601.us.archive.org/13/items/nationalb uilding01/in.gov.nbc.2016.vol1.digital.pdf

Central Electricity Authority. (2017). Growth of Electricity Sector in India From 1947-2017.
Retrieved

from http://www.cea.nic.in/reports/others/planning/pdm/ growth_2017.pdf

CEPT University. (2016). Impact of Building Energy Codes At the City Level Energy Efficiency Interventions in Cities Impact of Building Energy Codes At the City Level: Energy Efficiency Interventions in Cities_ 2016.

Evans, S., Liddiard, R., \& Steadman, P. (2019). Modelling a whole building stock: domestic, nondomestic and mixed use. Building Research and Information, 47(2), 156-172. https://doi.org/10.1080/09613218.2017.1410424

Government of India. (1950). Constitution of India. Retrieved from http://mohua.gov.in/cms/acts.php

Heiple, S., \& Sailor, D. J. (2008). Using building energy simulation and geospatial modeling techniques to determine high resolution building sector energy consumption profiles. Energy and Buildings, 40(8), 1426-1436. https://doi.org/10.1016/j.enbuild.2008.01.005

Hong, L., Zhou, N., Fridley, D., Feng, W., \& Khanna, N. (2014). Modeling China's Building Floor-Area Growth and the Implications for Building Materials and Energy Demand. 2014 ACEEE Summer Study on Energy Efficiency in Buildings, 146-157. https://doi.org/10.1016/j.wear.2004.06.002

International Energy Agency. (2017). World Energy Balances 2017. https://doi.org/10.1016/S13596454(03)00117-4

Kumar, S., Kapoor, R., Rawal, R., Seth, S., \& Walia, A. (2010). Developing Energy Conservation Building Code Implemetation Strategy in India. Energy Conservation and Commercialization (ECO-III). Retrieved from http://eco3.org/wpcontent/plugins/downloadsmanager/upload/Developing an ECBC Implementation Strategy in India- Report No.1028.pdf

Li, W., Zhou, Y., Cetin, K., Eom, J., Wang, Y., Chen, G., \& Zhang, X. (2017). Modeling urban building energy use: A review of modeling approaches and procedures. Energy, 141, 2445-2457. https://doi.org/10.1016/j.energy.2017.11.071

Lim, H. (2017). Prediction of Urban-Scale Building Energy Performance with a StochasticDeterministic-Coupled Approach. Retrieved from https://scholar.colorado.edu/cgi/viewcontent.cgi?ar ticle $=1083 \&$ context $=$ cven_gradetds

Rawal, R. (2013). ECOnirman \& third party assessors : innovative approaches to energy code compliance and enforcement in India. Eceee 2013 Summer Study: Rethink, Renew, Restart, (December 2015), 1329-1337. Retrieved from http://www.eceee.org/

Rawal, R., Vaidya, P., Ghatti, V., Manu, S., \& Chandiwala, S. (2013). ECOnirman \& third party assessors: innovative approaches to energy code 
compliance and enforcement in India. Eceee 2013 Summer Study: Rethink, Renew, Restart, (December 2015), 1329-1337. Retrieved from http://www.eceee.org/

Rawal, R., Vaidya, P., Ghatti, V., Ward, A., Group, T. W., Seth, S., ... Foundation, E. (2012). Energy Code Enforcement for Beginners : A Tiered Approach to Energy Code in India. Aceee, (2012 Summer Study), 313-324.

Tornberg, J., \& Thuvander, L. (2012). A GIS energy model for the building stock of Goteborg Jonas. (January 2005).

U.S. Department of Energy. (2016). EnergyPlus. Retrieved from https://energyplus.net/

UNFCCC. (2015). India's Intended Nationally Determined Contribution. Retrieved from https://www4.unfccc.int/sites/submissions/INDC/P ublished Documents/India/1/INDIA INDC TO UNFCCC.pdf

Zavrl, M. Š., Stegnar, G., Rakušček, A., \& Gjerkeš, H. (2016). A bottom-up building stock model for tracking regional energy targets-A case study of Kočevje. Sustainability (Switzerland), 8(10). https://doi.org/10.3390/su8101063 